\title{
Big Five Personality Characteristics and Its Effect on Task Conflict: A Case Study of Telecom Companies
}

\author{
NAILA SAYYED \\ MS Scholar, City University of Science and Information Technology, Peshawar \\ SAQIB SHAHZAD \\ Demonstrator, Institute of Business Studies and Leadership \\ Abdul Wali Khan University, Mardan \\ PhD-Scholar Institute of Management Sciences, Peshawar \\ saqibshahzad26@gmail.com \\ IHTESHAM KHAN \\ Assistant Professor and PhD-Scholar, Institute of Business Studies and Leadership \\ Abdul Wali Khan University, Mardan \\ ihtishamkhan@awkum.edu.pk \\ DR. JEHANGIR \\ Assistant Professor, Institute of Business Studies and Leadership \\ Abdul Wali Khan University, Mardan
}

\begin{abstract}
The study was an attempt to find out the effect of Myers Briggs Big Five personality characteristics on task conflict. The employees working in the telecommunication sector were considered as the population of the study. The employees were selected randomly. 180 questionnaires were distributed among employees. 127 properly filled questionnaires were received back from the respondents. The response rate was 70.56 percent. Simple Random sampling technique was used for the study. Analysis was used to testify the hypotheses of the study. As per the results of regression analysis big five personality characteristics were found to have significant effect on task conflict.
\end{abstract}

Keywords: Conscientiousness, Extraversion, Agreeableness, Neuroticism, Openness to Experience, task conflict

\section{Introduction}

In today's era of global competition and so much advancement in technology, the survival of organization has become a vital factor. Since employees are the real asset for any organization and the major source for sustainable competitive advantage. The employees need to be focusing on the job fully. If due to any reason the employee feels disturbed, then the bad consequences could be faced by the organization. These bad consequences could be because of conflicts. In the firms, March and Simon (1958), stated conflict as a collapse in the process of decision making, so that a person or team observe complexity in the selection of alternate. The $21^{\text {st }}$ century gives a wide experience by 
different source like internet and other approachable sources; now a large number of persons are now having the source to interrelate with others across the multi cultures (Templer et al., 2006). Due to these frequent communications, this culture dissimilarity is one of the main causes for the creation of conflict (Kaushal \& Kwantes, 2006).

\subsection{Research Problem}

Chen and Sheng (2010) found the relationship among different factor of conflicts but studying them together has not been focused up to the best of my knowledge (Holt \& DeVore, 2005). Researchers in the past have specifically focused on the developed countries (Ghorbani \& Razavi, 2011), but there is limited or very scarce research on developing countries.

\subsection{Research Questions}

- What is the impact of personality characteristics on task conflict?

- Do Big Five Personality characteristics promote conflicts in organization?

\subsection{Objectives of the Study}

- To investigate the effect of Personality characteristics on task conflict.

- To explore the effect of Conscientiousness on task conflict.

- To determine the effect of Extraversion on task conflict.

- To study the effect of Agreeableness on task conflict

- To examine the effect of Neuroticism on task conflict

- To evaluate the effect of Openness to Experience

\section{Literature Review}

According to Chen, Mei-Liang and Juin-Ming (2010) Conflict is Latin word which means different forces have a collision, which is disagreement and abrasion between group members (Forsyth, 1990). Webster Dictionary explains conflict as disagreement, war, unfriendliness, or opposition among irreconcilable forces (Chin-Lien $\mathrm{Wu}, 2003)$. According to Encyclopedia of Management, conflict is defined as a process that one individual or group realize that concentration or interest is opposite by the other group or individual (Chau-Chiuan Yu, 2005).There are certain definition of conflict which is given by the scholars. Conflict theory is the most important theory for any manager. Primarily it is rooted in the field of psychology, business and sociology, but not in education and communication. It is difficult to define conflict as it is complicated to an agreement about the definition of this term (Borisoff \& Victor, 1998). The simple way to identify the term "conflict" is to divide theories of conflict in situational functional and interactive. The followers of situational approach believe that a conflict as an expression or term under certain situation and those who view as functional think that a conflict serves a social function. The third theory views conflict as interactive. Many independent groups of researchers found and defined the five broad areas based on experimental, datadriven research. Agreeableness: Persons high in agreeableness are described as selfless, innocent, helpful, obedient, and "motivated by others "needs" (Costa \& McCrae, 1992). Conscientiousness: There is no known research investigate the relationship between conflict and conscientiousness. This is not completely incredible that conscientiousness is order, accomplishment orientation and dutifulness, characteristics that are unlikely to be linked conflict.

Fuller and Hall (1996) studied that difference in living behavior were a source of 
inter personal experience such as conflict. Since both incompetence and laziness (low conscientiousness) and extreme neatness (high conscientiousness) may be the cause of

conflict with a partner. Extraversion: Extraverts are usually encouraging, societal, energetic, fantastic, and concerned with other people (Costa \& McCrae, 1992; Watson \& Clark, 1997). In addition to these trait, several conceptualizations of extraversion also include adjectives such as prevailing, self-confident, dominant, and forceful (Costa \& McCrae, 1992; Trapnell \& Wiggins, 1990). Neuroticism: Neuroticism is described as the tendency to understanding emotions such as unhappiness, anger, guiltiness and fear. The most often study of the five-factor traits; neuroticism has also been study in association to conflict. It is related to both frequency of conflict and affects intensity related with that conflict (Bolger \& Zuckerman, 1995; McFatter, 1998; Suls et al., 1998). Openness to experience: Those people high on openness to experience are described as imaginative, interested, introspective, and conscientious to internal feelings (Costa \& McCrae, 1992; Hofstede, deRaad \& Goldberg, 1992). Openness is the least studied of the five-factor traits.

According to Antonioni (1998) several personalities traits with conflict in comfortable manner and others avoid it. People with a passive hostile personality tend to actively avoid conflict and feel uncomfortable confronting others in a conflicting situation. Individual feel angry or irritated but are not relaxed express that emotion. Emotions which are concealed for too long may erupt when control weakens and typically there is an explosion in a moment of heat, stress and pressure. John, Barbuto, Phipps and $\mathrm{Xu}$ (2010) point out that an integrate conflict management style completely mediates the relationship between neuroticism and leadership effectiveness and to some extent mediates the relationship between conscientiousness and leadership effectiveness. Personality and conflicts are related to each other in many ways.

\subsection{Hypotheses}

In the light of literature review the following hypotheses have been developed.

$\boldsymbol{H}_{1}$ : There is a significant effect of personality characteristics on task conflict.

$\boldsymbol{H}_{2}$ : There is a significant effect of conscientiousness on task conflict.

$\boldsymbol{H}_{3}$ : There is a significant effect of extraversion on task conflict.

$\boldsymbol{H}_{4}$ : There is a significant effect of agreeableness on task conflict.

$\boldsymbol{H}_{5}:$ There is a significant effect of neuroticism on task conflict.

$\boldsymbol{H}_{6}:$ There is a significant effect of openness to experience on task conflict.

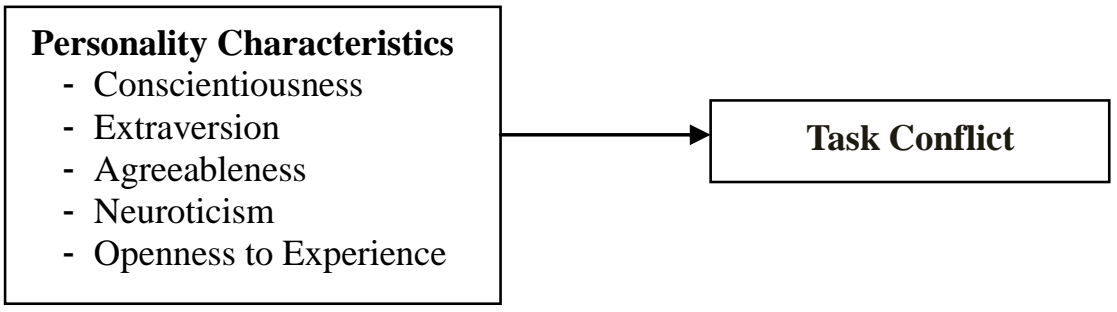

Figure 1: Theoretical Framework 


\section{Methodology}

The study was correctional in nature. Primary data was collected with the help of self-administered questionnaires. All employees of telecom companies formed the population of the study in two districts of KPK. The data was collected using simple random sampling technique (Ghorbani \& Razavi, 2011). 180 questionnaires were distributed among the respondent using simple random sampling technique. 127 filled questionnaires were returned. The questionnaire consists of two sections sec 1 was independent variable Personality characteristics which contains five sub fates i-e conscientiousness, extraversion, agreeableness, neuroticism and openness to experience. Personality characteristics questionnaire was adopted from Smith (2003) and measured with the help of 4 facets i-e agreeableness which was measured with 3 questions, extraversion which was measured with 3 questions, conscientiousness which was measured with 4 questions, neuroticisms which was measured with 5 questions and openness to experience with 5 questions. Sec 2 was dependent variables i-e task conflict. Task conflict questionnaire was adopted from Henning (2003), was measured with 5 questions.

\section{Results}

Table 4.1: Reliability Analysis

\begin{tabular}{|clcc|}
\hline S.No. & Variable & $\begin{array}{l}\text { Cronbach's } \\
\text { Alpha }\end{array}$ & Items \\
\hline 1 & Agreeableness & 0.870 & 3 \\
2 & Extraversion & 0.783 & 3 \\
3 & Conscientiousness & 0.729 & 4 \\
4 & Neuroticism & 0.714 & 5 \\
5 & Openness to Experience & 0.701 & 5 \\
6 & Task conflict & 0.739 & 5 \\
\hline
\end{tabular}

The above table 4.1 shows the reliability. Agreeableness was measured with 3 items the cronbach's alpha value is .870 reflecting that the variable is highly reliable and the questions asked were relevant to the variable. Extraversion was measured with 3 items the cronbach's alpha value is .783 reflecting that the variable is highly reliable and the questions asked are relevant to the variable. Conscientiousness was measured with 4 items the cronbach's alpha value is .729 reflecting that the variable is highly reliable and the questions asked are relevant to the variable. Neuroticism was measured with 5 items the cronbach's alpha value is .714 reflecting that the variable is highly reliable and the questions asked are relevant to the variable. Openness to experience was measured with 5 items the cronbach's alpha value is 3017 reflecting that the variable is highly reliable and the questions asked are relevant to the variable. Task conflict was measured with 5 items the cronbach's alpha value is .733 reflecting that the variable is highly reliable and the questions asked are relevant to the variable. 
Table 4.2: Correlation Analysis

\begin{tabular}{|lllllll|}
\hline & Conscientiousness & Extraversion & Agreeableness & Neuroticism & $\begin{array}{l}\text { Openness to } \\
\text { Experience }\end{array}$ & $\begin{array}{l}\text { Task } \\
\text { Conflict }\end{array}$ \\
\hline Conscientiousness & 1 & & & & & \\
Extraversion & $0.554^{* *}$ & 1 & & & & \\
Agreeableness & 0.452 & 0.342 & 1 & 1 & 1 \\
Neuroticism & $0.634^{* *}$ & 0.513 & 0.552 & 0.472 & 1 \\
Openness & to & 0.329 & 0.338 & $0.437^{* *}$ & $0.448^{* *}$ & 1 \\
Experience & 0.475 & $0.562^{* *}$ & 0.425 & 0.431 & & \\
Task Conflict & & & & & \\
\hline$* *$ Correlation is significant at the 0.01 level (2-tailed). & & & & \\
\hline
\end{tabular}

The above table 4.2 of correlation represents the strength of association between two variables. The correlation value of extraversion with conscientiousness is .554, means that strength of association between extraversion and conscientiousness is $55.4 \%$ the association is highly significant at $.01 \%$. The correlation value of agreeableness with conscientiousness is .452 and with extraversion is .432 means that strength of association between agreeableness and conscientiousness is $45.2 \%$ and with extraversion is $43.2 \%$. The correlation value of neuroticism with conscientiousness is .634, with extraversion is .513 and with agreeableness is .552 means that strength of association between neuroticism, conscientiousness, extraversion and agreeableness is $63.4 \%, 51.3 \%$ and $55.2 \%$ respectively. The correlation value of openness to experience with conscientiousness is .329 , with extraversion is .338 , with agreeableness is .437 and with neuroticism is .472 which means that strength of association between openness to experience, conscientiousness, extraversion, agreeableness and neuroticism is $32.9 \%$, $33.8 \%, 43.7 \%$ and $47.2 \%$ respectively. The correlation value of task conflict with conscientiousness is .475 , with extraversion is .562 , with agreeableness is .425 and with neuroticism is .431 and with openness to experience is .448 , which means that strength of association between task conflict, conscientiousness, extraversion, agreeableness, neuroticism and openness to experience is $47.5 \%, 56.2 \%, 42.5 \%, 43.1 \%$ and $44.8 \%$ respectively.

Table 4.3: Model Summary ${ }^{\mathrm{a}}$

\begin{tabular}{|lllll|}
\hline Model & $\mathrm{R}$ & $\mathrm{R}$ Square & $\begin{array}{l}\text { Adjusted } \\
\text { Square }\end{array}$ & $\mathrm{R}$ \\
\hline 1 & .537 & .562 & .511 & Std. Error of the Estimate \\
\hline
\end{tabular}

a. Predictors: (Constant), Personality Characteristics

In table 4.3 the personality characteristics were taken as independent variable and task conflict as dependent variable. $\mathrm{R}$ shows the strength of association. The value of $\mathrm{R}$ is .537 , which means that personality characteristics and task conflict are $53.7 \%$ percent correlated with each other. $\mathrm{R}^{2}$ shows variance explained in the dependent variable due to variation in the independent variable. The value of $\mathrm{R}^{2}$ is .562 , which means that personality characteristics causes $56.2 \%$ percent variation in task conflict. 
Table 4.4: ANOVA

\begin{tabular}{|lllllll|}
\hline \multirow{2}{*}{ Model } & & Sum & of & & & \\
\hline \multirow{2}{*}{1} & Regression & 19.677 & 2 & 8.633 & 171.987 & .000 \\
& Residual & 7.501 & 125 & .041 & & \\
& Total & 27.667 & 127 & & & \\
\hline
\end{tabular}

a. Predictors: (Constant), Personality Characteristics

b. Dependent Variable: Task Conflict

The above table 4.4 shows the results of ANOVA test. The test was used to know the model fitness. For the estimation of the results, the researcher should be sure about the model fitness. If the model is suitable then the results are trustable and if not then the model should be changed. The important value in this regard in the table is F-statistics. The standard in this regard is 4 . If the value of F-statistics is higher than 4 then the model is statistically significant and suitable for the estimation of results and if the value of F-statistics is lower than 4 then the model should be changed and it is not suitable for the verification of hypothesis. The F-statistics value in the above table is 171.897 . The pvalue is .000 , which means that the model is suitable and statistically significant.

Table 4.5: Coefficients ${ }^{\mathrm{a}}$

\begin{tabular}{|c|c|c|c|c|c|}
\hline \multirow[b]{2}{*}{ Model } & \multicolumn{2}{|c|}{ Unstandardized Coefficients } & \multirow{2}{*}{\begin{tabular}{|l}
$\begin{array}{l}\text { Standardized } \\
\text { Coefficients }\end{array}$ \\
Beta \\
\end{tabular}} & \multirow[b]{2}{*}{$\mathrm{t}$} & \multirow[b]{2}{*}{ Sig. } \\
\hline & $\mathrm{B}$ & Std. Error & & & \\
\hline (Constant) & 1.423 & .102 & & 09.071 & .000 \\
\hline Personality Characteristics & .182 & .053 & .133 & 4.713 & .001 \\
\hline
\end{tabular}

a. Dependent Variable: Task Conflict

The table 4.5 shows the results of coefficients that have been used in the regression test as the independent variables. The value of $\beta$ for personality characteristics is .182. It further shows that 1 unit change in the personality characteristics causes .182 units increase in task conflict. The t-value of personality characteristics is 4.713 ( $\mathrm{p}=.001$ ), shows that personality characteristics were found to have significant effect on task conflict.

Table 4.6: Model Summary ${ }^{\mathrm{a}}$

\begin{tabular}{|lllll|}
\hline Model & $\mathrm{R}$ & R Square & $\begin{array}{l}\text { Adjusted } \\
\text { Square }\end{array}$ & R \\
\hline 1 & .671 & .687 & .601 & .29711 \\
\hline
\end{tabular}

a. Predictors: (Constant), Conscientiousness, Extraversion, Agreeableness, Neuroticism, openness to experience

In this table 4.6 the factors of personality characteristics i.e conscientiousness, extraversion, agreeableness, neuroticism and openness to experience were taken as independent variables and task conflict as dependent variable. The value of $\mathrm{R}$ is .671 , 
which means that personality characteristics and task conflict are $67.1 \%$ percent associated with each other. The value of adjusted R-Square is .601 shows that $60.1 \%$ variation in task conflict is caused due to variation in the independent variables.

Table 4.7: ANOVA

\begin{tabular}{|c|c|c|c|c|c|c|}
\hline Model & & $\begin{array}{l}\text { Sum } \\
\text { Squares }\end{array}$ & Df & Mean Square & $\mathrm{F}$ & Sig. \\
\hline \multirow{3}{*}{1} & Regression & 26.765 & 2 & 9.323 & 24.71 & .000 \\
\hline & Residual & 8.9391 & 125 & .061 & & \\
\hline & Total & $34 . .667$ & 127 & & & \\
\hline
\end{tabular}

a. Predictors: (Constant), Conscientiousness, Extraversion, Agreeableness, Neuroticism, b. Dependent Variable: Task Conflict

\section{Openness to Experience}

The ANOVA table 4.7 shows that the F value $=24.71(\mathrm{p}=.000)$ means that the model is statistically highly significant.

Table 4.8: Coefficients ${ }^{\mathrm{a}}$

\begin{tabular}{|c|c|c|c|c|c|}
\hline \multirow[b]{2}{*}{ Model } & \multicolumn{2}{|c|}{$\begin{array}{l}\text { Unstandardized } \\
\text { Coefficients }\end{array}$} & \multirow{2}{*}{\begin{tabular}{|l}
$\begin{array}{l}\text { Standardized } \\
\text { Coefficients }\end{array}$ \\
Beta \\
\end{tabular}} & \multirow[b]{2}{*}{$t$} & \multirow[b]{2}{*}{ Sig. } \\
\hline & $\mathrm{B}$ & Std. Error & & & \\
\hline (Constant) & 1.423 & .102 & & 09.071 & .000 \\
\hline Conscientiousness & .125 & .033 & .113 & 3.813 & .001 \\
\hline Extraversion & .119 & .025 & .109 & 2.327 & .003 \\
\hline Agreeableness & .327 & .081 & .301 & 5.381 & .000 \\
\hline Neuroticism & .271 & .113 & .319 & 4.268 & .000 \\
\hline $\begin{array}{l}\text { Openness to } \\
\text { Experience }\end{array}$ & .319 & .105 & .298 & 7.251 & .000 \\
\hline
\end{tabular}

a. Dependent Variable: Task Conflict

The above table 4.8 shows that the $\beta=.125$ means that one unit increase in conscientiousness causes .125 units increase in task conflict, the $\beta=.119$ means that one unit increase in extraversion causes .119 units increase in task conflict, $\beta=.327$ means that one unit increase in agreeableness causes .327 units increase in task conflict, $\beta=.271$ means that one unit increase in neuroticism causes .271 units increase in task conflict, $\beta=.319$ means that one unit increase in openness to experience causes .319 units increase in task conflict. The $\mathrm{t}$ values for conscientiousness, extraversion, agreeableness, neuroticism and openness to experience respectively are $\mathrm{t}=3.813(\mathrm{p}=.001), \mathrm{t}=2.327$ $(\mathrm{p}=.003), \mathrm{t}=5.381(\mathrm{p}=.000), \mathrm{t}=4.268(\mathrm{p}=.000)$ and $\mathrm{t}=7.251 \quad(\mathrm{p}=.000)$. Hence show that all the values are significant which means that al factors of big five personality characteristics have significant effect on task conflict. All the hypotheses $\mathrm{v}$ been accepted. 


\section{Conclusion}

The study was conducted to analyze the effect of personality traits and organizational culture. The study was basically conducted on the telecom sector of Pakistan. The employees working in the telecom companies at Peshawar were the population of the study. 207 employees from telecom companies comprised of sample size of the study. Simple random technique was used. The data was collected by closed ended, structured questionnaire. 5 likert scale method was used in the questionnaire (strongly disagree, disagree, neutral, agree, and strongly agree). Reliability statistics was used to know the reliability of the variables, to check that whether the variables are reliable for the data collection. Correlation test was used to know the relationship among the dependent and independent variables. Regression test was used to know the cause and effect of the variables. As per the results of reliability test all the variables are reliable. The value of Cronbach's alpha is above $70 \%$ for all variables. As per the results of correlation test, organizational conflict has 83 percent positive relationship with organizational culture and this relationship is significant under 5 percent. Organizational conflict has 55 percent positive correlation with personality characteristics and also significant. According to the regression results of personality characteristics and organizational culture on organizational conflict, personality characteristics have insignificant effects on organizational conflict $(\mathrm{p}$-value $=.089)$. While organizational culture has significant effects on organizational conflict ( $\mathrm{p}$-value $=.000)$.

\section{References}

Antonioni, D. (1998). Relationship between the big five personality factors and conflict management styles. journal of management development, 9(4), 336-355.

Bolger, N., \& Zuckerman, A. (1995). A framework for studying personality in the stress process. Journal of Personality and Social Psychology,69, 890-902.

Bond, M. H., \& Smith, P. B. (1996). Cross-cultural social and organizational psychology. Annual Review of Psychology, 47, 205-235.

Borisoff, D., \&Victor, D.A. (1998). Conflict Management: A Communication Skills Approach. 2nd ed. Boston: Allyn and Bacon, 1998.

Chen, M.L., \& Sheng, H. (2010). The Effects of Personality Traits and Conflict Management on Organizational Commitment A Case Study of Taiwan FinanciaServices Personnel. The Journal of International Management Studies, 4(1), 10.

Chau-Chiuan Yu. (2005). Organizational Behavior, Taipei: Wu-Nan Book Co. Ltd., 5563.

Costa, P. T. Jr., \& McCrae, R. R. (1992). Revised NEO Personality Inventory (NEOPI- R) and NEO Five-Factor (NEO-FFI) Inventory Professional Manual. Odessa, FL: PAR.

Deal, T. E., \& Kennedy, A. (1982). Corporate Culture,The Rites and Rituals of Corporate Life. Reading: M.A: Addison Wesley.

Forsyth, D. R. (1990). Group Dynamics, Pacific Grove CA.: Brooks/Cole Publishing.

Fuller, B. E., \& Hall, F. J. (1996). Differences in personality type and roommate compatibility as predictors of roommate conflict. Journal of College Student Development, 37, 510-518. 
Ghorbani, M \& Razavi, N.H.(2011). The Study of the Relationship between Organizational Culture and Conflict Management. Middle-East Journal of Scientific Research 10 (6), 711-717.

Hofstee, W. K. B., DeRaad, B., \& Goldberg, L. R. (1992). Integration of the big five and circumplex approaches to trait structure. Journal of Personality and Social Psychology, 63, 146-163.

Hofstede, G. (1980) Culture's consequences: International differences in work-related values, Beverly Hills, CA: Sage.

Hofstede, G. (2001). Culture's consequences (2nd ed.). Thousand Oaks, CA: Sage.

Holt, J. L., \& DeVore, C. J. (2005). Culture, gender, organizational role, and styles of conflict resolution: A meta-analysis. International Journal of Intercultural Relations, 29(2), 165-197.

Kagitcibasi, C., \& Berry, J. W. (1989). Cross-cultural psychology: Current research and trends. Annual Review of Psychology, 40, 493-531.

Kaushal, R., \& Kwantes, C. T. (2006). The role of culture and personality in choice of conflict management strategy. International Journal of Intercultural Relations, 30(5), 579-603.

Lewis, D. S. (1992). Communicating organizational culture. Australian Journal of Communication, 19(2), 47-57.

Lewis, D. S. (1996). The organizational culture saga - from OD to TQM: a critical review of the literature. Part 1 - concepts and early trends. Leadership \& Organization Development Journal, 17(1), 12-19.

March, J. G., \& Simon, H. A. (1958). Organizations. New York: Wiley.

McAdams, D. P. (1995). What do we know when we know a person? Journal of Personality, 63, 365-396.

McFatter, R. M. (1998). Emotional intensity: Some components and their relations to extraversion and neuroticism. Personality \& Individual Differences, 24, 747-758.

Peters, T. J. \& Waterman, R. H. Jr. (1982). In Search of Excellence, Sydney: Harper and Row.

Sathe, V. (1983). Implications of corporate culture: a manager's guide to action. Organizational Dynamics, 12, 5-23.

Schein, E. H. (1984). Organizational psychology. Englewood, Cliffs, NJ: Prentice-Hall.

Suls, J., Martin, R., \& David, J. (1998). Person-environment fit and its limits: Agreeableness, neuroticism, and emotional reactivity to interpersonal conflict. Personality and Social Psychology Bulletin, 24, 88-98.

Templer, K., Tay, C., \& Chandrasekar, N. A. (2006). Motivational cultural intelligence, realistic job preview, realistic living conditions preview, and crosscultural adjustment.Group \& Organization Management, 31(1), 154-173.

Trapnell, P. D., \& Wiggins, J. S. (1990). Extension of the interpersonal adjective scales to include the big five dimensions of personality.Journal of Personality and Social Psychology, 59, 781-790.

Triandis, H. C. (1990). Cross-cultural studies on individualism and collectivism, In: J. J. Berman, (Ed.), Nebraska symposium on motivation, 1989: Cross-cultural perspectives. Current theory and research in motivation (37, 41-133). Lincoln, 
NE: University of Nebraska Press.

Watson, D., \& Clark, L. A. (1997).Extraversion and its positive emotional core. In R. Hogan, J. Johnson, \& S. Briggs (Eds.), Handbook of personality psychology. San Diego: Academic Press. 